\title{
Article
}

\section{The influence of Kinesio taping on muscle fatigue in individuals with low back pain: A randomised controlled trial}

Macedo, Liane Brito, Richards, James, Tezoni Borges, Daniel, Alencar Melo, Samara, Dantas Reis, Daniela and Simoes Brasileiro, Jamilson

Available at http://clok.uclan.ac.uk/36570/

Macedo, Liane Brito, Richards, James ORCID: 0000-0002-4004-3115, Tezoni Borges, Daniel, Alencar Melo, Samara, Dantas Reis, Daniela and Simoes Brasileiro, Jamilson (2021) The influence of Kinesio taping on muscle fatigue in individuals with low back pain: A randomised controlled trial. The Journal of Back and Musculoskeletal Rehabilitation, 34 (4). pp. 613-621. ISSN 1053-8127

It is advisable to refer to the publisher's version if you intend to cite from the work. http://dx.doi.org/10.3233/BMR-200207

For more information about UCLan's research in this area go to

http://www.uclan.ac.uk/researchgroups/ and search for < name of research Group>.

For information about Research generally at UCLan please go to http://www.uclan.ac.uk/research/

All outputs in CLoK are protected by Intellectual Property Rights law, including Copyright law. Copyright, IPR and Moral Rights for the works on this site are retained by the individual authors and/or other copyright owners. Terms and conditions for use of this material are defined in the policies page. 
The influence of Kinesio taping on muscle fatigue in individuals with low back pain: A randomised controlled trial

Liane Brito Macedo ${ }^{\mathrm{a}, \mathrm{c}^{*}}$, Jim Richards ${ }^{\mathrm{b}}$, Daniel Tezoni Borges ${ }^{\mathrm{c}}$, Samara Alencar Melo $^{c}$, Daniela Dantas Reis ${ }^{\mathrm{d}}$, Jamilson Simões Brasileiroc ${ }^{\mathrm{c}}$

a. Faculty of Health Sciences of Trairi, Federal University of Rio Grande do Norte, Santa Cruz, Brazil.

b. Allied Health Research unit, University of Central Lancashire, Preston, United Kingdom.

c. Physiotherapy Department, Federal University of Rio Grande do Norte, Natal, Brazil.

d.Technology Center, Federal University of Rio Grande do Norte, Natal, Brazil.

\section{*Corresponding author:}

Universidade Federal do Rio Grande do Norte

Faculdade de Ciências da Saúde do Trairí

Rua Teodorico Bezerra, Santa Cruz/RN

CEP: 59.200-000

e.mail: lianebmacedo@yahoo.com.br

Phone: +55 (84) 3342-2287 


\section{Abstract}

OBJECTIVE: To evaluate the effect of different taping techniques on back muscle fatigue in people with low back pain.

METHODS: Sixty women with chronic non-specific low back pain were randomly assigned to four groups with 15 in each; control (CG), Kinesio Taping (KT) with tension (KTT), KT no tension (KTNT) and Micropore ${ }^{\circledR}$ (MP), which were applied over the erector spinae muscles. The median frequency (MF) fatigue slopes of the longissimus muscle and sustained contraction time during a trunk fatigue test (Ito test), and pain using the numerical pain rating scale (NPRS) were collected at three time points: pre-treatment, three and ten days after intervention at a university laboratory.

RESULTS: Significant differences were seen in the MF slopes between groups $(\mathrm{p}=0.01, \eta 2=0.20)$, with the KTT showing a mean difference $(\mathrm{MD}=0.31, \mathrm{p}=0.04)$ and KTNT $(\mathrm{MD}=0.28, \mathrm{p}=0.04)$ compared with $\mathrm{CG}$. Significant reductions in NPRS were seen between time points $(\mathrm{p}<0.001, \eta 2=0.28)$, with a reduction between pre and 3 days $(\mathrm{MD}=1.87, \mathrm{p}<0.001)$, and pre and 10 days $(\mathrm{MD}=1.38, \mathrm{p}<0.001)$, with KTT and KTNT both showing clinically important changes.

CONCLUSION: KT, with or without tension, has a tendency to reduce back muscle fatigue and reduce pain in individuals with chronic non-specific low back pain.

Keywords: bandages, electromyography, lumbar spine, muscle fatigue. 


\section{Introduction}

Individuals with low back pain (LBP) often have biomechanical and musculoskeletal dysfunction and have been reported to have poor back muscle endurance [1-3]. Several studies have reported greater fatigability of the lumbar extensor muscles in this population compared to healthy subjects [3-6]. This phenomenon may be associated with muscle atrophy [7], which may result in instability of the trunk and consequently increases tissue strain and pain [8].

Muscle fatigue has been reported to be a continuous process which can be recorded using surface electromyography (EMG) [4,9]. Typical measures include Median Frequency (MF) and Mean Power Frequency (MPF). When muscles fatigue the MF declines, which has been associated with altered muscle-fibre recruitment or physiological changes in the muscle [4]. The MF has been shown to be less sensitive to noise and more sensitive to physiological changes [10], and its slope during a sustained contraction has been shown to be a valid and reliable index of muscle fatigue [11]. Several studies have used the MF slope to assess back muscle fatigue in individuals with LBP and to provide comparisons with healthy subjects $[3,5,11,12]$.

Clinicians and individuals with LBP are continuously seeking interventions which are able to decrease pain and enhance musculoskeletal performance to help in the management of LBP. Amongst these, different taping techniques have been proposed which aim to improve patient pain and function. Kinesio Taping (KT) has been reported to improve muscle performance, increase joint stability, reduce pain [1316], and change motor unit recruitment [17]. The therapeutic mechanisms of Kinesio Taping on LBP have not been fully elucidated, however the literature relates any purported benefits to the activation of cutaneous mechanoreceptors, explained through 
pain gate theory $[14,16,17]$. However, there is still a lack of strong evidence on the effects of KT in the treatment of musculoskeletal conditions $[18,19,20]$.

Studies that have investigated the influence of KT on back muscle fatigue in individuals with LBP are scarce. Àlvarez-Àlvarez et al. [21] found that KT appears to improve the time to failure of the extensor muscles of the trunk, however this study only recruited healthy individuals. Hagen et al. [22] evaluated the effect of taping on fatigue in individuals with LBP and concluded that back muscle endurance was greater with elastic tape applied when compared to no tape, however there was no difference when using rigid tape. They concluded that, although there was a statistical difference, these changes did not exceed measurement error, and such interventions warrant further investigation. However, currently little or no information exists on the effect of different taping techniques in individuals with low back pain.

Therefore, this study aimed to evaluate the effects of different taping techniques on pain and back muscle fatigue in individuals with low back pain, by exploring the electromyography activity of the longissimus muscle, sustained time during a fatigue test and pain.

\section{Methods}

\subsection{Trial Design}

A four-arm, single blinded randomised controlled trial conducted at a university laboratory between March and August 2018.

\subsection{Participants}


A convenience sample comprised of 60 women aged between 18 and 50 years old (mean age of $25.64 \pm 6.0$ years; mean Body Mass Index BMI of $22.5 \pm 2.5 \mathrm{~kg} / \mathrm{m}^{2}$ ) with chronic non-specific low back pain were included in this study. Only women were selected as low back pain is more common in females than males [23]. Exclusion criteria were; any red flags involving the spine, use of corticosteroids in the last two weeks or anti-inflammatory medication in the last 24 hours, pregnant, allergy or intolerance to the KT, or had undergone taping techniques in the treatment of their LBP. The women could not been in their menstrual cycle or the premenstrual period, have a BMI over 30 and have a NPRS less than 2. Furthermore, volunteers were excluded if they did not reach a minimum of 20 seconds of sustained contraction during the fatigue test on the first day of evaluation.

Participants were required to give informed consent, according to Resolution 466/2012 of the National Health Council and the Declaration of Helsinki, after being informed of the study aims. Participants that met the inclusion criteria, signed the consent form, filled out the evaluation form containing personal and anthropometric data and underwent an allergy test to Kinesio Taping®. The study was approved by the local ethics committee (protocol number 1.213.864) and registered on clinicaltrials.gov (NCT03463200).

\subsection{Intervention}

The participants were randomised to four intervention groups: control group (CG), KT with tension group (KTT), KT no tension group (KTNT) and Micropore ${ }^{\circledR}$ group (MP). The randomised allocation of participants to the four groups was 
performed using www.randomization.com by an independent assessor, and the sequence of allocation was sealed in opaque envelopes which were opened immediately before the first intervention. We chose to use a no tension group to check the need for tension when applying the technique, and a Micropore ${ }^{\circledR}$ group to compare the technique to a minimal or placebo intervention, since Micropore ${ }^{\circledR}$ is a medical/surgical tape, hypoallergenic, breathable, adhesive and very easy to apply and remove.

Three evaluators participated in the study: evaluator 1 was responsible for the participant assessments; evaluator 2 was responsible for the interventions; and evaluator 3 for the statistical analysis, who was blinded to the conditions.

The intervention methodology was carried out in accordance to Macedo et al [16]. The KTT group received an application of Kinesio Taping with a slight stretch of approximately $10-15 \%$, in the form of an "I" over the erector spinae muscles bilaterally $[16,22,24]$. To apply the tape, the participants were asked to stay seated and perform a trunk flexion with rotation to the opposite side of the tape application. The tape was fixed with tension from the posterior superior iliac spine to the T12 with an initial and final anchor [25]. Participants in the KTNT group received an application of KT similar to the KTT group, however they were asked to hold a neutral pose and no tension was applied to the tape (Figure 1). For the participants in the Micropore ${ }^{\circledR}$ group, the application was performed in the same way as the KTT group. The tape was left in place for three days for all participants who received a taping intervention and it was not renewed. The control group participants did not receive any intervention.

\section{INSERT FIGURE 1}

\subsection{Evaluation}


Three assessments were performed: on day one (pre-treatment), day 3 (participants still using the tape) and after 10 days (a follow-up after 7 days of tape removal). The outcomes included; the numerical pain rating scale (NPRS) which was assessed based on the last 24 hours [25], the median frequency (MF) fatigue slope of the longissimus muscle, and the sustained contraction time during the fatigue test. To assess the longissimus muscle fatigue, the participants were instructed to perform a lumbar trunk fatigue test which was first reported by Ito et al [26]. This has been reported to be a valid variation of the Sorensen test [27] and was chosen because it is easy to perform, does not require any equipment apart from a pad and produces less overload on the spine when compare to the Sorensen test. In addition, this has not been shown to increase lumbar pain or result in participants' withdrawal from studies [2629].

For the lumbar trunk fatigue test the participants were positioned in a prone position on a plinth with a pad below the lower abdomen in order to rectify the lumbar lordosis, and the arms were kept alongside the body (Figure 2). They were instructed to maintain a position without the sternum or arms making contact with the plinth, hold the trunk, and flex the neck as much as possible [26]. Prior to data collection participants were allowed to perform one trial for familiarization. Each participant then performed a single assessment task. The maximum time during this contraction was recorded, with a minimum allowed time of 20 s and maximum time limited to 300 s, during which the EMG activity of the longissimus muscle was recorded.

\section{INSERT FIGURE 2}

To assess the EMG activity, the participant's skin was shaved and cleaned with $70 \%$ alcohol prior to electrode placement. A 16-channel signal conditioner model 
(Telemyo direct transmission system, Noraxon®, USA) with a resolution of 16-bit and common mode rejection $(\mathrm{CMR})>100 \mathrm{~dB}$ was used. Signals were captured with a sampling frequency of $1500 \mathrm{~Hz}$, amplified 1000 times and filtered with a bandpass of 10 - $500 \mathrm{~Hz}$. Passive self-adhesive surface electrodes (4 x $2.2 \mathrm{~cm})$ were applied in a bipolar arrangement, with an inter-electrode distance of $2 \mathrm{~cm}$ (Noraxon®, USA). The electrodes were placed bilaterally over the left and right longissimus muscles, in accordance with the SENIAM guidelines [30], and all signal processing was performed using MyoResearch 3.8 (Noraxon®, USA).

The analysis of the frequency spectrum within the EMG signals was determined using the Fast Fourier Transformation method. From this the median frequency (MF) was found using a window length of one second [31]. The rate of reduction in the median frequency was found over the successive time windows using a linear regression using the mean of the data for the right and left sides [31], which has been reported to be a reliable index of muscle fatigue [11]. This slope was normalized to the initial MF due to the differences in skin impedance and subcutaneous layers between subjects $[11,32]$. This was achieved by dividing the MF during each time window by the initial MF, which is represented by the intercept of the MF regression line, and then multiplied by $100[3,11,27,32]$.

\subsection{Statistical Analysis}

All statistical analyses were performed using SPSS 20.0. A mixed methods ANOVA (4x3) was used to analyse the differences among the four groups (CG, KTT, KTNT, MP) over the three time points (Pre, 3 days, 10 days) and the effect of group, time, and group $\mathrm{x}$ time interactions for the normalized median frequency slope, sustained contraction time and NPRS were found. The homogeneity of variance was 
verified by the Levene test. When the assumption of sphericity was violated, significance was adjusted using Greenhouse-Geisser. The effect sizes were calculated using partial eta-square ( $\eta 2)$, and when significant main effects were seen post hoc pairwise comparisons were performed using a Bonferroni correction with a 0.05 significance level.

\section{Results}

One hundred and thirty individuals were assessed for eligibility, 70 were excluded according to the exclusion criteria. The remaining 60 were assigned to the different groups $(\mathrm{CG} n=15, \mathrm{KTT} n=15, \mathrm{KTNT} n=15, \mathrm{MP} n=15)$. See Figure 3 for the consort diagram and Table 1 for the mean and homogeneity of each variable at baseline.

INSERT FIGURE 3

\section{INSERT TABLE 1}

The mixed methods ANOVA showed no significant interactions between group and time for pain $(\mathrm{F}=0.63, \mathrm{p}=0.70, \eta 2=0.03)$, sustained contraction time $(\mathrm{F}=0.85$, $\mathrm{p}=0.52, \eta 2=0.04)$ and $\mathrm{MF}$ fatigue slope $(\mathrm{F}=0.47, \mathrm{p}=0.83, \eta 2=0.03)$, with a power of 0.6, however significant main effects were seen for group and time. Specifically, significant differences were seen between groups for the MF fatigue slope $(F=3.86$, $\mathrm{p}=0.01, \eta 2=0.20$ ), further post hoc testing showed a significant difference between the CG group and both the KTT and KTNT groups ( $\mathrm{p}=0.04$ and $\mathrm{p}=0.03)$, respectively, with no significant differences seen between the MP group and the other 3 groups ( $p>0.05)$. No significant differences were seen for sustained contraction time between the three assessment time points $(\mathrm{p}=0.14)$ or group $(\mathrm{p}=0.09)$. However, NPRS did show a statistically significant difference between the three assessment time points ( $\mathrm{F}=21.5$, $\mathrm{p}<0.001, \eta 2=0.27)$. Further post hoc tests showed a reduction between pre and 3 days 
$(p<0.001)$ and between pre and 10 days $(p<0.001)$, with the difference in NPRS between pre and 3 days for both KTT and KTNT exceeding the threshold for a clinically important change [32], although no significant differences were seen between the groups.

\section{INSERT TABLE 2}

\section{Discussion}

The aim of this study was to explore the effect of different taping techniques on back muscle fatigue and pain in individuals with low back pain. Our results showed no significant interactions between group and time for any variable, however, a significantly greater MF fatigue slope was seen in the control group compared with both the KTT and KTNT groups, and pain was also reduced over the three time points with a clinically important change whilst wearing the KT tape. In addition no significant differences were seen for the sustained contraction time.

Electromyography has been widely used to estimate fatigue [4] and the median frequency slope has been shown to be a valid and reliable index [11]. According to De Luca [9] changes that happen in the muscle during fatigue are reflected in the properties of myoelectric signals. Moreover, this method has been shown to have excellent reproducibility and correlation with clinical measures, showing its clinical applicability to detect changes in LBP populations [33,34]. Several studies have reported back muscle fatigue in individuals with low back pain and in healthy subjects using electromyography $[3,5,11,12]$. However, to our knowledge, there is no study that has examined the effects of taping on back muscle fatigue in individuals with low back pain using EMG. 
Paoloni et al [17] assessed three different groups that used Kinesio Taping, exercise or Kinesio Taping plus exercise. Although they used electromyography, they evaluated muscle function during a flexion-relaxation pattern and did not consider fatigue. In addition, Kang et al [35] examined the influence of postural taping on kinematic and electromyography activity in a group of physical therapists with low back pain whilst performing patient transfers. However, they used Root Mean Square (RMS) to estimate the magnitude of muscle activity, rather than a measure of fatigue.

To the authors' knowledge no study has considered frequency indices such as the median frequency slope to assess the effects of taping in individuals with low back pain, although data does exist using sustained contraction time as a measure of muscle fatigue $[14,21,22]$. Hagen et al [22] performed a crossover trial and compared the differences in fatigue time during the Sorensen test for three different conditions: no tape, rigid tape and elastic tape. Their results showed a difference between the no tape and elastic tape groups, but no differences were seen between the rigid and elastic tape groups. However the magnitude of the differences found was small and did not exceed the measurement error.

Castro-Sánchez et al [14] compared the effects of Kinesio Taping and sham taping on individuals with low back pain. Among the variables analysed, they observed trunk muscle fatigue using the McQuade test, one week after tape application and four weeks after the tape had been removed. Their results showed an improvement at oneweek for fatigue time in the experimental group, which increased by 13 seconds, whereas the sham group worsened by 9 seconds. Four weeks later, the between-group difference was 18 seconds in favour of the experimental group.

Àlvarez-Àlvarez et al. [21] conducted a randomized, controlled, doubled- 
blinded clinical trial to determine the influence of $\mathrm{KT}$ on the resistance to fatigue in the lumbar extensor muscles in ninety-nine healthy subjects. Although this was not conducted on individuals with low back pain, they did find an improvement in the time to failure of the back muscles using the Sorensen test for those with KT compared to a control group, with no significant changes in a placebo group.

These previous finding support the changes observed in the MF slope in this current study, which showed a between-group difference for the control group when compared to the KTT and KTNT groups, indicating that the KT, with or without tension, has a positive influence on the rate of muscle fatigue. For the MP group no differences were observed, either between the control group or between the KT groups. This lack of statistical difference in the MP group may suggest a lesser or placebo effect, as the results were similar to the KT groups. For the comparison between time points, we observed that the decline in the MF slope seemed to be greater over time in the CG, with a value of $0.17 \mathrm{~Hz} / \mathrm{s}$, whereas the greatest decline for the other groups was 0.06 $\mathrm{Hz} / \mathrm{s}$, although these differences were not statistically significant.

Concerning the sustained contraction time during the Ito test, which may be considered an alternate measure of back muscle fatigue, we found no differences between the four groups or time points. Although all the studies cited above used time to failure of back muscles as a fatigue variable, all found positive results in KT groups, which differs from our results. This may be due to the current study using the Ito test as opposed to the Sorensen test, although the mean data from the four groups indicated that the control group had a shorter time to fatigue at the different time points, whereas the KT groups showed no reduction.

When considering pain, our results showed a reduction over the assessment time 
points in all groups, although no significant differences between groups was seen. However, the greatest reductions were seen in the KT groups, with a 2.0 point reduction between pre and 3 days for KTT, and 2.6 between pre and 3 days for KNTN, which according to Ostelo et al [36] may be considered to be above the threshold of a minimal clinically important change. The MP group also showed a reduction of 1.4 and 1.5 between pre and three days and pre and ten days, respectively, however these changes were not statistically significant and were below the threshold of a clinically important change. These findings would suggest that there may be a relationship between a reduction in pain and better motor unit recruitment with some evidence in the literature supporting this [37]. This may indicate that when individuals used KT, either with or without tension, they had a less steep MF slope possibly due to improved sensation and control leading to pain reduction.

Among the limitations of the current study was that there was only a 10 day follow-up, so the longer term effects remain unknown. This current study also only considered the effects on women, and although LBP is more common in women than men, these results may provide a useful guide to clinical practice in male patients also, however further work needs to be carried out to confirm this.

\section{Conclusion}

In conclusion, Kinesio Taping seems to influence back muscle fatigue in individuals with chronic non-specific low back pain, whether with or without tension, and provides clinically important changes in pain. However, it is also important to note that there was no statistical difference between KT groups compared to the Micropore ${ }^{\circledR}$ group, therefore this study cannot support any superiority in one taping technique over another. 


\section{Acknowledgements}

We thank the volunteers who participated in this study and the CAPES for financial support.

\section{Conflict of interest}

The authors report no conflicts of interest.

\section{References}

[1] Alschuler KN, Neblett R, Wiggert E, Haig AJ, Geisser ME. Flexionrelaxation and clinical features associated with chronic low back pain: a comparison of different methods of quantifying flexion-relaxation. Clin $\mathbf{J}$ Pain. 2009; 25(9): 760-766.

[2] Biering-Sorensen F. Physical measurements as risk indicators for low-back trouble over a one-year period. Spine. 1984; 9:106-119.

[3] Silva RA, Vieira ER, Cabrera M, Altimari LR, Aguiar AF, Nowotny AH, et al. Back muscle fatigue of younger and older adults with and without chronic low back pain using two protocols: a case-control study. J Electromyogr Kinesiol. 2015; 25(6): 928-936.

[4] De Luca CJ. Use of the surface EMG signal for performance evaluation of back muscles. Muscle \& Nerve. 1993; 16: 210-216.

[5] Ramos LAV, França FJR, Callegari B, Burke TN, Magalhães MO, Marques AP. Are lumbar multifidus fatigue and transversus abdominis activation similar in patients with lumbar disc herniation and healthy controls? A case 
control study. Eur Spine J. 2016; 25(5): 1435-1442.

[6] Abboud J, Nougarou F, Pagé I, Cantin V, Massicotte D, Descarreaux M. Trunk motor variability in patients with non-specific chronic low back pain. Eur J Appl Physiol. 2014; 114(12): 2645-2654.

[7] Jubany J, Marina M, Angulo-Barroso R. Electromyographic and Kinematic Analysis of Trunk and Limb Muscles During a Holding Task in Individuals With Chronic Low Back Pain and Healthy Controls. PM\&R. 2017; 9:11061116.

[8] Granata KP, Gottipati P. Fatigue influences the dynamic stability of the torso. Ergonomics. 2008; 51: 1258-1271.

[9] De Luca CJ. Myoelectrical manifestations of localized muscular fatigue in humans. Crit. Rev. Biomed. Eng. 1984; 11(4): 251-279.

[10] Hagg GM. Interpretation of EMG spectral alterations and alteration indexes at sustained contraction. J Appl Physiol. 1992; 73: 1211-1217.

[11] Larivière C, Arsenault AB, Gravel D, Gagnon D, Loisel P. Evaluation of measurement strategies to increase the reliability of EMG spectral indices to assess back muscle fatigue and recovery. J Electromyogr Kinesiol. 2002;12: 91-102.

[12] Larivière C, Arsenault AB, Gravel D, Gagnon D, Loisel P. Surface electromyography assessment of back muscle intrinsic properties. J Electromyogr Kinesiol. 2003; 13(4): 305-318.

[13] Kase K, Wallis J, Kase T. Clinical therapeutic aplications of the kinesio taping method. 2nd ed. Kinesio Taping Association. 2003.

[14] Castro-Sánchez AM, Lara-Palomo IC, Matarán-Peñarrocha GA, Fernández-Sánchez M, Sánchez-Labraca N, Arroyo-Morales M. Kinesio 
Taping reduces disability and pain slightly in chronic non-specific low back pain: A randomised trial. J Physiother. 2012; 58(2): 89-95.

[15] Kachanathu SJ, Alenazi AM, Seif HE, Hafez AR, Alroumim AM. Comparison between kinesio taping and a traditional physical therapy program in treatment of nonspecific low back pain. J Phys Ther Sci. 2014; 26(8): 1185-1188.

[16] Macedo LB, Richards J, Borges DT, Melo SA, Brasileiro JS. Kinesio taping reduces pain and improves disability in low back pain patients: a randomised controlled trial. Physiother. 2019; 105:65-75.

[17] Paoloni M, Bernetti A, Fratocchi G, Mangone M, Parrinello L, Del Pilar Cooper M, et al. Kinesio Taping applied to lumbar muscles influences clinical and electromyographic characteristics in chronic low back pain patients. Eur J Phys Rehabil Med. 2011; 47(2): 237-244.

[18] Ramírez-Vélez R, Hormazábal-Aguayo I, Izquierdo M, González-Ruíz, K, Correa-Bautista JE, García-Hermoso A. Effects of kinesio taping alone versus sham taping in individuals with musculoskeletal conditions after intervention for at least one week: a systematic review and metaanalysis. Physiother. 2019; 105(4): 412-420.

[19] Nelson NL. Kinesio taping for chronic low back pain: a systematic review. J Bodyw Mov Ther. 2016; 20(3): 672-681.

[20] Luz Júnior MA, Almeida MO, Santos RS, Civile VT, Costa LOP. Effectiveness of kinesio taping in patients with chronic nonspecific low back pain: a systematic review with meta-analysis. Spine. 2019; 44(1): 6878.

[21] Álvarez-Álvarez S, San José F, Rodríguez-Fernández AL, GüeitaRodríguez J, Waller BJ. Effects of Kinesio® Tape in low back muscle 
fatigue: randomized, controlled, doubled-blinded clinical trial on healthy subjects. J Back Musculoskelet Rehabil. 2014; 27(2): 203-212. therapeutic taping on back extensor muscle endurance in patients with low back pain: a randomized, controlled, crossover trial. J Orthop Sport PhysTher. 2015; 45(3): 215-219.

[23] Hoy D, Brooks P, Blyth F, Buchbinder R. The epidemiology of low back pain. Best pract res clin rheumatol. 2010; 24(6): 769-781.

[24] Parreira PCS, Costa LCM, Takahashi R, Hespanhol Junior LC, Luz Junior MA, Silva TM et al. Kinesio Taping to generate skin convolutions is not better than sham taping for people with chronic non-specific low back pain: A randomised trial. J Physiother. 2014;60(2):90-96.

[25] Added MAN, Costa LOP, Fukuda TY, Freitas DG, Salomão EC, Monteiro RL, et al. Efficacy of adding the Kinesio Taping method to guideline-endorsed conventional physiotherapy in patients with chronic nonspecific low back pain: a randomised controlled trial. BMC Musculoskelet Disord. 2013;14:301.

[26] Ito T, Shirado O, Suzuki H, Takahashi M, Kaneda K, Strax TE. Lumbar trunk muscle endurance testing: An inexpensive alternative to a machine for evaluation. Arch Phys Med Rehabil. 1996; 77:75-79.

[27] Müller R, Strässle K, Wirth B. Isometric back muscle endurance: an EMG study on the criterion validity of the Ito test. J Electromyogr Kinesiol. 2010; 20(5): 845-850.

[28] Demoulin C, Grosdent S, Smeets R, Verbunt J, Jidovtseff B, Mahieu G, et al. Muscular performance assessment of trunk extensors: A critical 
appraisal of the literature. In: Low Back Pain. InTech. 2012;141-166.

[29] Arab AM, Salavati M, Ebrahimi I, Mousavi ME. Sensitivity, specificity and predictive value of the clinical trunk muscle endurance tests in low back pain. Clin Rehabil. 2007;21(7):640-647.

[30] Hermens HJ, Freriks B, Disselhorst-Klug C, Rau G. Development of recommendations for SEMG sensors and sensor placement procedures. J Electromyogr Kinesiol. 2000; 10(5): 361-374.

[31] Kankaanpää M, Laaksonen D, Taimela S, Kokko S-M, Airaksinen O, Hanninen O. Age, sex, and body mass index as determinants of back and hip extensor fatigue in the isometric Sorensen back endurance test. Arch Phys Med Rehabil. 1998;79(9):1069-1075.

[32] Coorevits P, Danneels L, Cambier D, Ramon H, Vanderstraeten G. Assessment of the validity of the Biering-Sorensen test for measuring back muscle fatigue based on EMG median frequency characteristics of back and hip muscles. J Electromyogr Kinesiol. 2008;18:997-1005.

[33] Dedering Å, Németh G, Harms-Ringdahl K. Correlation between electromyographic spectral changes and subjective assessment of lumbar muscle fatigue in subjects without pain from the lower back. Clin Biomech. $1999 ; 14(2): 103-111$

[34] Koumantakis GA, Arnall F, Cooper RG, Oldham JA. Paraspinal muscle EMG fatigue testing with two methods in healthy volunteers. Reliability in the context of clinical applications. Clin Biomech. 2001; 16(3): 263-266.

[35] Kang M-H, Choi S-H, Oh J-S. Postural taping applied to the low back influences kinematics and EMG activity during patient transfer in physical therapists with low back pain. J Electromyogr Kinesiol. 2013; 23: 787-793. 
[36] Ostelo RWJG, Deyo RA, Stratford P, Wanddell G, Croft P, Von Korff M. Interpreting change scores for pain and functional status in low back pain: towards international consensus regarding minimal important change. Spine 2008;33:90-94. [istep

[37] Tucker K, Larsson A-K, Oknelid S, Hodges P. Similar alteration of motor unit recruitment strategies during the anticipation and experience of pain. Pain. 2012; 153(3), 636-643. 
Table 1. Values of mean and standard deviation (SD) of all variables and groups evaluated at baseline and the homogeneity between them.

\begin{tabular}{|c|c|c|c|c|}
\hline Variable & $\begin{array}{c}\text { CG } \\
(n=15)\end{array}$ & $\begin{array}{l}\text { KTT } \\
(n=15)\end{array}$ & $\begin{array}{l}\text { KTNT } \\
(n=15)\end{array}$ & $\begin{array}{c}\text { MP } \\
(n=15)\end{array}$ \\
\hline Age (years) & $24.4(5.0)$ & $25.6(6.9)$ & $24.9(5.9)$ & $26.5(6.1)$ \\
\hline Weight (Kg) & $61.2(9.5)$ & $58.8(7.5)$ & $57.0(9.4)$ & $60.8(7.4)$ \\
\hline Height (m) & $1.63(0.06)$ & $1.61(0.05)$ & $1.60(0.06)$ & $1.65(0.05)$ \\
\hline BMI $\left(\mathrm{Kg} / \mathrm{m}^{2}\right)$ & $22.9(2.6)$ & $22.5(2.3)$ & $22.1(2.6)$ & $22.4(2.5)$ \\
\hline NPRS (cm) & $5.2(1.5)$ & $4.3(1.9)$ & $5.1(2.1)$ & $4.8(1.7)$ \\
\hline MF slope $(\mathrm{Hz} / \mathrm{s})$ & $-0.67(0.39)$ & $-0.40(0.20)$ & $-0.45(0.30)$ & $-0.61(0.23)$ \\
\hline Sustained contraction time (s) & $40.1(18.0)$ & $52.9(26.4)$ & $54.7(30.7)$ & $54.0(24.2)$ \\
\hline
\end{tabular}

CG: control group; KTT: Kinesio Taping with tension group; KTNT: Kinesio Taping No Tension group; MP: Micropore group; BMI: Body Mass Index; NPRS: Numerical Rating Scale; MF: Median Frequency. 
Table 2. Mean and standard deviation (SD) and ANOVA results of median frequency slope and fatigue time for the four groups at the 3 time points.

\begin{tabular}{|c|c|c|c|c|c|c|c|c|c|c|c|c|c|c|}
\hline & \multicolumn{3}{|c|}{ CG $(n=15)$} & \multicolumn{3}{|c|}{ KTT $(n=15)$} & \multicolumn{3}{|c|}{ KTNT $(n=15)$} & \multicolumn{3}{|c|}{ MP (n=15) } & $\frac{\text { p value }}{\text { Group }}$ & $\begin{array}{c}\text { Effect size } \\
\text { Group }\end{array}$ \\
\hline & Pre & $\begin{array}{c}3 \\
\text { days }\end{array}$ & $\begin{array}{c}10 \\
\text { days }\end{array}$ & Pre & $\begin{array}{c}3 \\
\text { days }\end{array}$ & $\begin{array}{c}10 \\
\text { days }\end{array}$ & Pre & $\begin{array}{c}3 \\
\text { days }\end{array}$ & $\begin{array}{c}10 \\
\text { days }\end{array}$ & Pre & $\begin{array}{c}3 \\
\text { days }\end{array}$ & $\begin{array}{c}10 \\
\text { days }\end{array}$ & $\begin{array}{c}\text { Group } \\
x \\
\text { time }\end{array}$ & $\begin{array}{c}\text { Group } \\
\mathrm{x} \\
\text { time }\end{array}$ \\
\hline NPRS (0-10) & $\begin{array}{l}5.2 \\
(1.5)\end{array}$ & $\begin{array}{l}3.7 \\
(2.1)\end{array}$ & $\begin{array}{l}4.4 \\
(2.6)\end{array}$ & $\begin{array}{l}4.3 \\
(1.9)\end{array}$ & $\begin{array}{l}2.3 \\
(1.8)\end{array}$ & $\begin{array}{l}2.8 \\
(2.0)\end{array}$ & $\begin{array}{l}5.1 \\
(2.1)\end{array}$ & $\begin{array}{l}2.5 \\
(1.9)\end{array}$ & $\begin{array}{l}3.3 \\
(2.7)\end{array}$ & $\begin{array}{l}4.8 \\
(1.7)\end{array}$ & $\begin{array}{l}3.4 \\
(2.1)\end{array}$ & $\begin{array}{l}3.3 \\
(2.6)\end{array}$ & 0.70 & 0.03 \\
\hline MF slope (Hz/s) & $\begin{array}{l}-0.67 \\
(0.39)\end{array}$ & $\begin{array}{l}-0.72 \\
(0.35)\end{array}$ & $\begin{array}{l}-0.84 \\
(0.52)\end{array}$ & $\begin{array}{l}-0.40 \\
(0.20)\end{array}$ & $\begin{array}{l}-0.45 \\
(0.19)\end{array}$ & $\begin{array}{l}-0.46 \\
(0.25)\end{array}$ & $\begin{array}{l}-0.45 \\
(0.30)\end{array}$ & $\begin{array}{l}-0.44 \\
(0.20)\end{array}$ & $\begin{array}{l}-0.50 \\
(0.19)\end{array}$ & $\begin{array}{l}-0.61 \\
(0.23)\end{array}$ & $\begin{array}{l}-0.55 \\
(0.31)\end{array}$ & $\begin{array}{l}-0.66 \\
(0.27)\end{array}$ & 0.83 & 0.03 \\
\hline $\begin{array}{l}\text { Sustained } \\
\text { contraction time } \\
\text { (s) }\end{array}$ & $\begin{array}{l}40.1 \\
(18)\end{array}$ & $\begin{array}{r}34.7 \\
(13.1)\end{array}$ & $\begin{array}{l}28.5 \\
(14.2)\end{array}$ & $\begin{array}{l}52.9 \\
(26.4)\end{array}$ & $\begin{array}{l}55.6 \\
(30.1)\end{array}$ & $\begin{array}{l}53.5 \\
(28.5)\end{array}$ & $\begin{array}{l}54.7 \\
(30.7)\end{array}$ & $\begin{array}{l}56.1 \\
(36.3)\end{array}$ & $\begin{array}{l}53.1 \\
(32.4)\end{array}$ & $\begin{array}{l}54.0 \\
(24.2)\end{array}$ & $\begin{array}{c}50.1 \\
(26.8)\end{array}$ & $\begin{array}{l}49.2 \\
(27.0)\end{array}$ & 0.52 & 0.04 \\
\hline
\end{tabular}

CG: control group; KTT: Kinesio Taping with tension group; KTNT: Kinesio Taping No Tension group; MP: Micropore group; MF: Median Frequency. 
Figure 1. Kinesio Taping application without tension (left picture) and with tension (right picture).

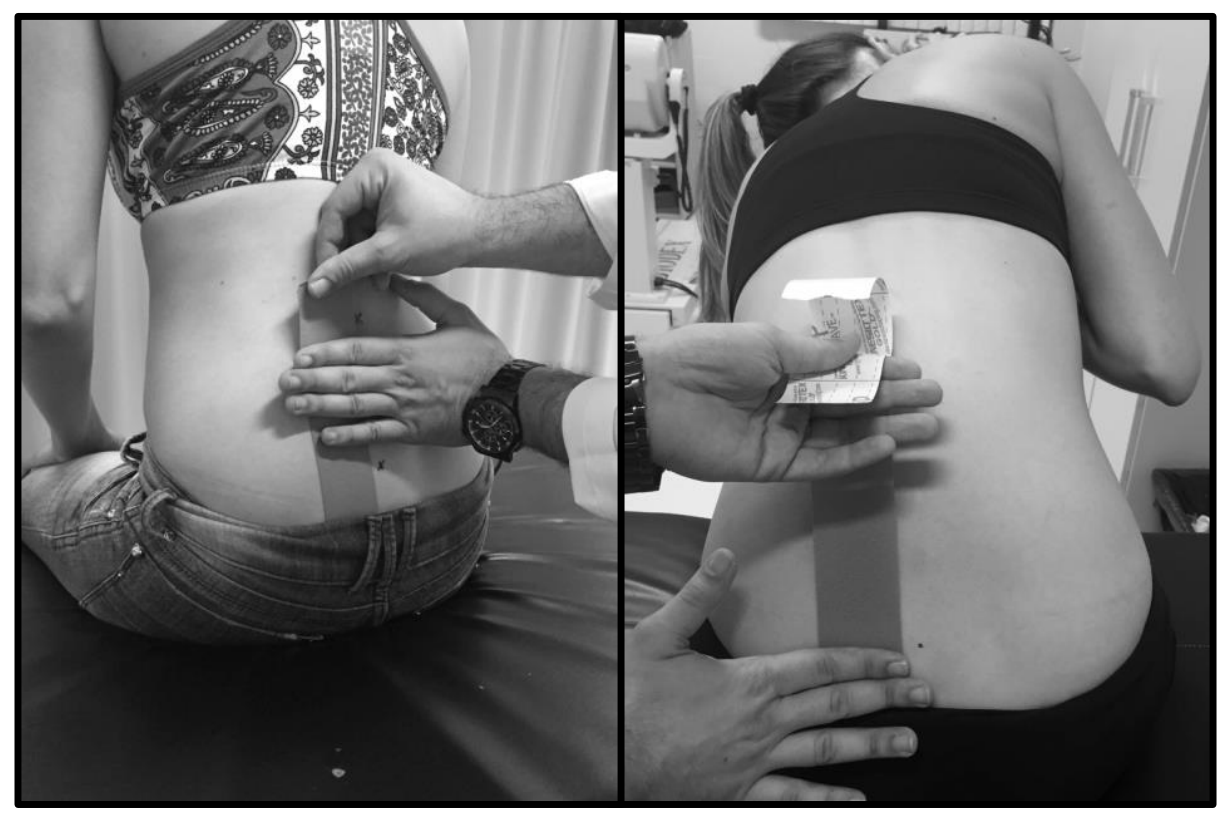


Figure 2. Lumbar trunk muscle endurance test.

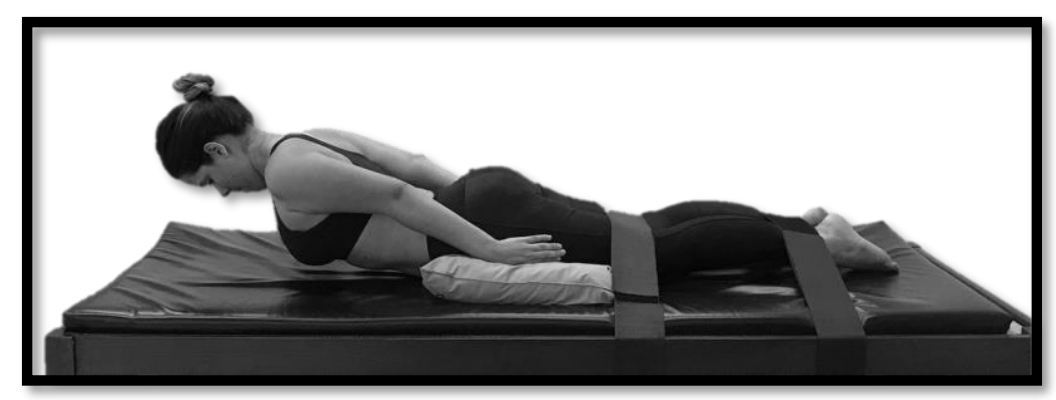


Figure 3. Flow diagram of the study.

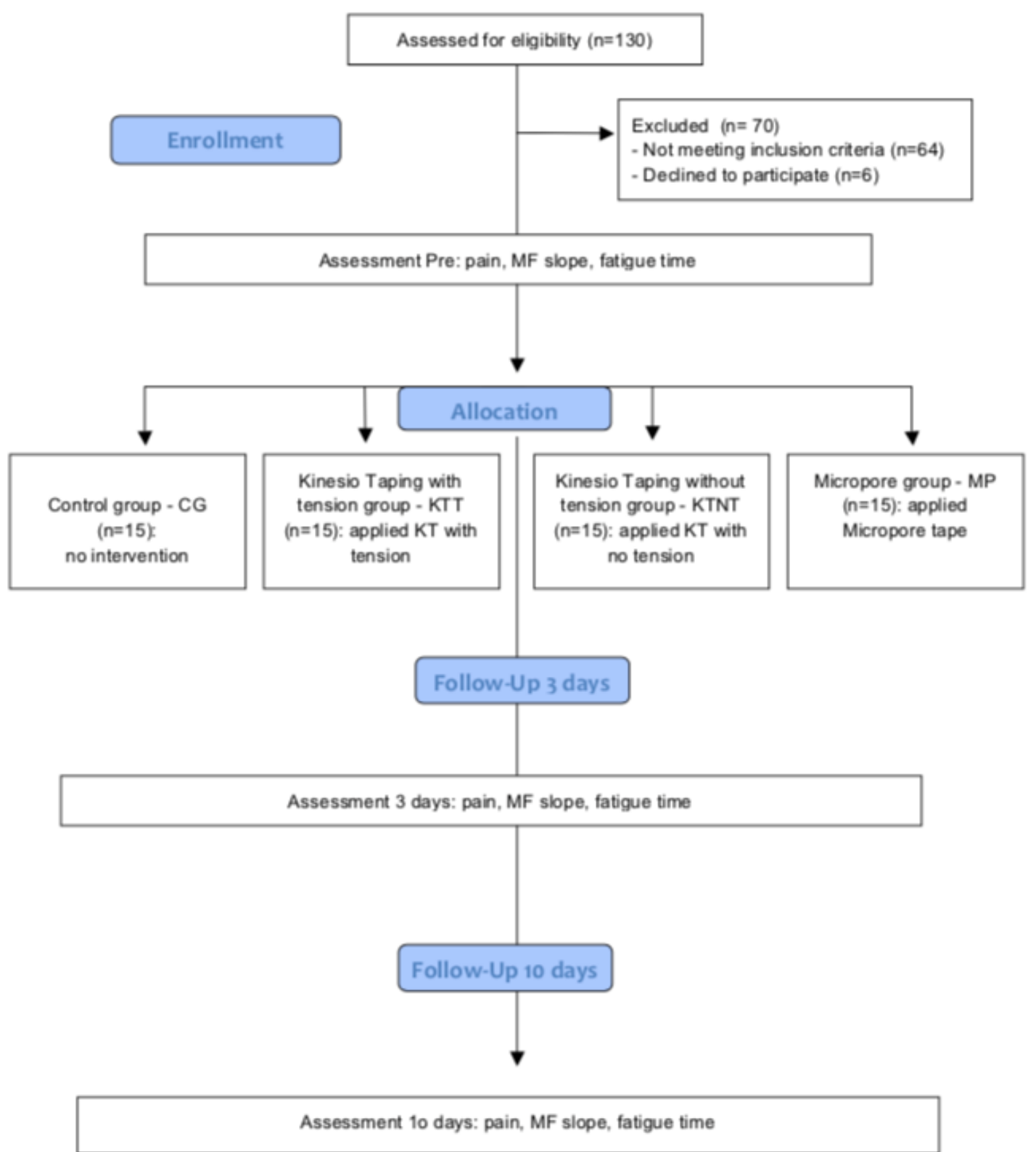

